\title{
Review of 1,447 Breast Augmentation Patients Using PERTHESE Silicone Implants
}

\author{
Jorge Miguel Psillakis · Paulo Henrique Facchina • \\ Paulo Kharmandayan · Luis Trillo • \\ Waldecir Chiarelo Canzi · Herberti Rosique Aguiar
}

Received: 30 March 2009/ Accepted: 27 July 2009/Published online: 17 September 2009

(c) The Author(s) 2009. This article is published with open access at Springerlink.com

\begin{abstract}
Introduction A survey of surgeons in Brazil on their experience with PERTHESE silicone breast implants was performed.

Materials and methods Surgeons that used PERTHESE implants between 2002 and 2008 were surveyed on the shape and volume of the implants used, surgical incision site, surgical plane of insertion, key postoperative complications, and surgeon and patient satisfaction.

Results The survey had a response rate of $20 \%$, with ten surgeons reporting data on 1447 patients. The majority of the implants used were $200-300 \mathrm{cc}$, round, and high profile. Preference for the traditional inframammary incision site (47\% of patients) was favored over transaxillary (33\%) and periareolar (19\%), and both subglandular (55\%) and submuscular (44\%) planes of insertion were used. Over $97 \%$ of surgeons and patients were satisfied with the results and surgeons indicated that the implants were easy to use.

Conclusions This review demonstrates that these implants are safe, maybe easier to introduce than other implants, and result in a high level of surgeon and patient satisfaction.
\end{abstract}

J. M. Psillakis · P. H. Facchina · P. Kharmandayan - L. Trillo ·

H. R. Aguiar

Plastic Surgery Area, Department of Surgery, School

of Medical Sciences, Universidade Estadual de Campinas

(FCM-UNICAMP), São Paulo, Brazil

W. C. Canzi

Canzi Plastic Surgery Clinic, Passo Fundo, Rio Grande do Sul, Brazil

J. M. Psillakis $(\square)$

Rua Helena, 218 conj. 209, 04552-050 Vila Olímpia, São Paulo, SP, Brazil

e-mail: jorgepsi@terra.com.br
Keywords Breast augmentation - Silicone prosthesis . Mammary implants · Capsular contraction .

Breast implants · Breast surgery $\cdot$ Silicone implants

Today breast augmentation is performed all over the world. According to the American Society of Plastic Surgeons (ASPS) approximately 307,000 women in the United States (US) alone underwent breast augmentation surgery in 2008 and the demand for silicone implants is rising; the number of silicone breast implants increased from 35\% in 2007 to $47 \%$ in 2008. It is estimated that Brazil is today the second major market for breast implants, with approximately 96,000 breast augmentation surgeries reported from September 2007 to August 2008, according to the Brazilian Society of Plastic Surgery (Sociedade Brasileira de Cirurgia Plástica [SBCP]). In Brazil, with the approval of the SBCP and the Brazilian Sanitary Surveillance Agency (Agência Nacional de Vigilância Sanitária [ANVISA]), silicone implants were used throughout the 14-year US Federal Drug Administration-issued silicone implant moratorium (1992-2006).

In 2002, the PERTHESE ${ }^{\circledR}$ silicone implant line, manufactured by PEROUSE PLASTIE Laboratories in France, was adopted by Brazilian surgeons. The specific advantages of this silicone implant line include the close approximation in weight and consistency of the normal breast and the highperformance medical-grade silicone elastomer envelope that provides greater tear propagation resistance than the conventional silicone elastomer [1]. These implants have a trilaminar silicone envelope that consists of an internal and an external layer of highly mechanically resistant medicalgrade silicone elastomer and an intermediate barrier layer to significantly reduce gel bleed. The microtexturing gives the implant a relatively smooth feel, is identical from implant to 
implant, and is thought to help the implant remain soft while in contact with tissue [1]. The microtextured PEROUSE PLASTIE products include the PERTHESE classic line of round implants with a low (TX), moderate (MX), or high profile (540), and the PERTHESE Esthea line of anatomical implants with a full (AX), high (EHP), or superhigh profile (ESHP) (Table 1).

In 2005, Auclair and Staub [2] published an article on the use of these implants in France but until now no data have been published on the use of PERTHESE implants in Brazil. We analyzed data collected from ten surgeons on a total of 1447 patients who underwent breast augmentation surgery in Brazil from 2002 through 2008. Surgeons were surveyed on the implant shape and volume used, surgical incision site, surgical plane of insertion, key postoperative complications, and surgeon and patient satisfaction.

\section{Method}

A questionnaire was sent to 50 surgeons in Brazil who were using PERTHESE silicone breast implants. The questionnaire requested the following information on patients who underwent surgery: implant shape and volume, surgical incision site, surgical plane of insertion, key postoperative complications, and surgeon and patient satisfaction. Each surgery was performed according to a surgeon's free will and previous experience as well as the patient's wishes. The following data were collected:

1. Implant shape and volume, determined by desire of the patient and advice of the surgeon based on the anatomical conditions of the patient (Table 2)

2. Surgical incision site (inframammary, periareolar, or transaxillary) (Table 3), determined by the surgeon after discussion with the patient about potential scarring

3. Surgical plane of insertion (submuscular plane or subglandular) according to surgeon's and patient's preference (Table 3)

Table 1 Description of available study breast implants

\begin{tabular}{ll}
\hline $\begin{array}{l}\text { Shape of implant } \\
\text { Profile/Style }\end{array}$ & Volume (cc) \\
\hline $\begin{array}{l}\text { Classic (Round) } \\
\text { High/540 }\end{array}$ & $100,125,150,175,200,230,260,280$, \\
& $300,325,350,400,440,500$ \\
Moderate/MX & 225 \\
Low/TX & $185,200,220$ \\
Esthea (Anatomical) & \\
Full/AX & $190,210,240,260,285,300$ \\
Super High/ESHP & 295,355 \\
High/EHP & 225,275 \\
\hline
\end{tabular}

4. Patient's and surgeon's overall satisfaction with the surgery (excellent, good, regular, or unsatisfied) (Table 4)

5. Ease of implantation compared to other breast implants (Table 5)

6. Number of cases with postoperative complications, including immediate complications such as seroma, hematoma, infection, and reoperations, and late complications such as capsular contracture, Baker grade I, II, III, and IV, and rupture (Table 6)

\section{Survey Results}

Data were collected on 1447 breast augmentation patients who underwent surgery in Brazil between 2002 and 2008. The data were analyzed for implant shape and volume, surgical incision site, surgical plane of insertion, postoperative complications, and surgeon and patient satisfaction.

The majority $(95.9 \%)$ of the implants used were round and high profile (Table 2). Seventy-eight percent of the round, high-profile implants had a volume range of 200$300 \mathrm{cc}$. The remainder of the patients received round, moderate-profile $(0.1 \%)$, round, low-profile $(0.5 \%)$, anatomical, full-profile $(2.0 \%)$, anatomical, superhigh-profile $(0.4 \%)$, and anatomical, high-profile $(1.1 \%)$ implants.

The results on surgical access show a preference for the traditional inframammary incision site $(47.1 \%)$, followed by transaxillary $(33.6 \%)$ and periareolar (19.4\%; Table 3). Subglandular and submuscular planes of insertion were used to a similar extent, with $55.4 \%$ subglandular and $44.6 \%$ submuscular (Table 3).

Over $97 \%$ of surgeons and patients were satisfied with the surgery results, with $84.0 \%$ of surgeons and $79.6 \%$ of patients rating the surgery results as excellent. Less than $1 \%$ of the surgeons and patients were not satisfied with the surgery results (Table 4).

When surveyed about ease of use, the majority of surgeons $(66.6 \%)$ indicated that the PERTHESE implant was easier to implant that other breast implants (Table 5).

The reported complications included capsular contracture (hard breast to palpation), implant malposition/asymmetry, hematoma, seroma, and reoperation. Capsular contracture, the most common complication found in this study, was reported in $61(4.2 \%)$ patients: $42(2.9 \%)$ patients experienced Baker grade III and 19 (1.3\%) experienced Baker grade IV (Table 6). Several patients also experienced seromas (6 patients, $0.4 \%$ ) or hematomas (4 patients, $0.3 \%$ ). Late postoperative asymmetry occurred in $18(1.2 \%)$ patients. During the study period, $4(0.3 \%)$ patients underwent reoperation and no cases of implant rupture were observed. 
Table 2 Study implants, shape, and volume

\begin{tabular}{|c|c|c|}
\hline $\begin{array}{l}\text { Shape of implant } \\
\text { Profile/Style }\end{array}$ & Volume (cc) & $\begin{array}{l}\text { Cases }(\%) \\
N=1447\end{array}$ \\
\hline \multicolumn{3}{|l|}{ Round } \\
\hline \multirow[t]{14}{*}{ High/540 } & 100 & $6(0.4)$ \\
\hline & 125 & $9(0.6)$ \\
\hline & 150 & $32(2.2)$ \\
\hline & 175 & $61(4.2)$ \\
\hline & 200 & $113(7.8)$ \\
\hline & 230 & $248(17.1)$ \\
\hline & 260 & $302(20.9)$ \\
\hline & 280 & $159(11.0)$ \\
\hline & 300 & $318(22.0)$ \\
\hline & 325 & $26(1.8)$ \\
\hline & 350 & $85(5.9)$ \\
\hline & 400 & $22(1.5)$ \\
\hline & 440 & $5(0.3)$ \\
\hline & 500 & $1(0.1)$ \\
\hline Subtotal & & $1387(95.9)$ \\
\hline Moderate/MX & 225 & $2(0.1)$ \\
\hline Subtotal & & $2(0.1)$ \\
\hline \multirow[t]{3}{*}{ Low/TX } & 185 & $2(0.1)$ \\
\hline & 200 & $1(0.1)$ \\
\hline & 220 & $4(0.3)$ \\
\hline Subtotal & & $7(0.5)$ \\
\hline \multicolumn{3}{|l|}{ Esthea } \\
\hline \multirow[t]{6}{*}{ Full/AX } & 190 & $3(0.2)$ \\
\hline & 210 & $1(0.1)$ \\
\hline & 240 & $5(0.3)$ \\
\hline & 260 & $3(0.2)$ \\
\hline & 285 & $14(1.0)$ \\
\hline & 300 & $3(0.2)$ \\
\hline Subtotal & & $29(2.0)$ \\
\hline \multirow[t]{2}{*}{ Super High/ESHP } & 295 & $4(0.3)$ \\
\hline & 355 & $2(0.1)$ \\
\hline Subtotal & & $6(0.4)$ \\
\hline Total & & $1447(100)$ \\
\hline \multirow[t]{2}{*}{ High/EHP } & 225 & $6(0.4)$ \\
\hline & 275 & $10(0.7)$ \\
\hline Subtotal & & $16(1.1)$ \\
\hline
\end{tabular}

${ }^{\text {a }}$ With microtextured envelope

\section{Discussion}

After extensive laboratory research by the French company PEROUSE PLASTIE, the PERTHESE line of cohesive silicone gel breast implants was manufactured. Since the introduction of these breast implants in Brazil in 2002, there has been an increasing amount of available data on their use; however, these data have not been reported. This survey study on the use of PERTHESE implants in 1447
Table 3 Surgical access and plane of insertion

\begin{tabular}{ll}
\hline & Cases $(\%)(N=1447)$ \\
\hline Surgical access & \\
Inframammary & $681(47.1)$ \\
Transaxillary & $486(33.6)$ \\
Periareolar & $280(19.4)$ \\
Surgical plane & \\
Subglandular & $802(55.4)$ \\
Submuscular & $645(44.6)$ \\
\hline
\end{tabular}

Table 4 Surgeon and patient satisfaction $(N=1447)$

\begin{tabular}{lllll}
\hline & Excellent $(\%)$ & Good (\%) & Regular (\%) & Unsatisfied (\%) \\
\hline Surgeons & 84.0 & 14.6 & 0.9 & 0.6 \\
Patients & 79.6 & 17.7 & 2.1 & 0.6 \\
\hline
\end{tabular}

Table 5 Surgeon evaluation of ease of use

\begin{tabular}{ll}
\hline $\begin{array}{l}\text { Ease of implantation compared } \\
\text { to other breast implants }\end{array}$ & Surgeons $(\%)(N=9)$ \\
\hline Easier & $6(66.7)$ \\
No difference & $3(33.3)$ \\
\hline
\end{tabular}

Table 6 Postoperative complications

\begin{tabular}{ll}
\hline Type of complication & Cases $(\%)(N=1447)$ \\
\hline Capsular contracture & \\
Baker III & $42(2.9)$ \\
Baker IV & $19(1.3)$ \\
Baker III/IV & $61(4.2)$ \\
Implant malposition/asymmetry $^{\mathrm{a}}$ & $18(1.2)$ \\
Seroma, drainage needed $_{\text {Hematoma, drainage needed }}$ & $6(0.4)$ \\
Reoperation $^{\text {Implant change }}$ & $4(0.3)$ \\
Due to asymmetry $^{\mathrm{a}}$ & $3(0.2)$ \\
Rupture $^{\mathrm{b}}$ & $1(0.1)$ \\
\end{tabular}

${ }^{\text {a }}$ One asymmetry case resulted in reoperation

b Implant rupture was not evident for implants that were removed and was not suspected in the remaining population

patients suggests that these implants are safe, easier to introduce than other implants, and result in a high level of surgeon and patient satisfaction.

Consistent with these findings, a review of the breast implant literature finds an overall high level of patient satisfaction with breast implant surgery and a relatively low level of postoperative complications (Table 7). As in 
Table 7 Review of the literature

\begin{tabular}{|c|c|c|c|c|c|c|c|}
\hline & [3] & [4] & {$[5]$} & {$[6]$} & [7] & [8] & Current study \\
\hline Study method & Survey & MRI $^{\mathrm{d}}$ study & Clinical trial & Comparative trial & Clinical trial & Clinical trial & Survey \\
\hline Country & Canada & Sweden & US & Sweden & US & US & Brazil \\
\hline Patients $(N)$ & 118 & 144 & 492 & 80 & 552 & 455 & 1,447 \\
\hline Follow-up (years) & Up to 2 & $5-9$ & 3 & $4-6$ & 6 & 6 & Up to 6 \\
\hline Device & Style $410^{\mathrm{a}}$ & Style $410^{\mathrm{a}}$ & Style $410^{\mathrm{a}}$ & Style $410^{\mathrm{b}}$ and Vertex ${ }^{\mathrm{d}}$ & MemoryGel $^{\mathrm{c}}$ & Natrelle $^{\mathrm{a}} \mathrm{I}$ & PERTHESE $^{\mathrm{e}}$ \\
\hline \multicolumn{8}{|l|}{ Volume (cc) } \\
\hline Range & Not reported & $190-475$ & Not reported & $240-500$ & Not reported & Not reported & $100-500$ \\
\hline Median & & 280 & & 300 & & & 270 \\
\hline \multicolumn{8}{|l|}{ Implant location $^{\mathrm{f}}$} \\
\hline Subglandular & $32 \%$ & $31 \%$ & $16 \%$ & $72 \%$ & Not reported & $30 \%$ & $55 \%$ \\
\hline Submuscular & $68 \%$ & $58 \%$ & $84 \%$ & $28 \%$ & & $70 \%$ & $45 \%$ \\
\hline Unknown & 0 & $11 \%$ & 0 & 0 & & 0 & 0 \\
\hline Other & 0 & 0 & 0 & 0 & & $<1 \%$ & 0 \\
\hline \multicolumn{8}{|l|}{ Incision site ${ }^{\mathrm{f}}$} \\
\hline Inframammary & $81 \%$ & $74 \%$ & $87 \%$ & $86 \%$ & Not reported & $46 \%$ & $47 \%$ \\
\hline Transaxillary & 0 & $3 \%$ & $<1 \%$ & $<2 \%$ & & $13 \%$ & $34 \%$ \\
\hline Periareolar & $4 \%$ & 0 & $12 \%$ & $13 \%$ & & $39 \%$ & $19 \%$ \\
\hline Unknown & 0 & $23 \%$ & 0 & 0 & & 0 & 0 \\
\hline Other & $15 \%$ & 0 & $1 \%$ & 0 & & $2 \%$ & 0 \\
\hline Overall patient satisfaction & Not reported & $97 \%$ & $98 \%$ & $99 \%$ & $98 \%$ & $95 \%$ & $97 \%$ \\
\hline $\begin{array}{l}\text { Capsular contracture, } \\
\text { Baker III/IV }\end{array}$ & $0 \%$ & $6 \%$ & $2 \%$ & $23 \%$ & $10 \%$ & $15 \%$ & $4 \%$ \\
\hline $\begin{array}{l}\text { Implant malposition/ } \\
\text { asymmetry }\end{array}$ & $1 \%$ & Not reported & $3 \%$ & Not reported & 0 & $8 \%$ & $1 \%$ \\
\hline Implant removal & 0 & $<1 \%$ & $5 \%$ & Not reported & $8 \%$ & $13 \%$ & $<1 \%$ \\
\hline
\end{tabular}

${ }^{a}$ Manufactured by Allergan

${ }^{\mathrm{b}}$ Manufactured by Eurosilicone

c Manufactured by Mentor

${ }^{\mathrm{d}}$ MRI = magnetic resonance imaging

e Manufactured by PEROUSE PLASTIE

${ }^{\mathrm{f}}$ Implant location and incision site percentages are based on total number of devices implanted (Bengtson et al. [5], 983 devices; Spear et al. [8], 908 devices; Hedén et al. [4], 286 devices) or total number of patients (Niechajev et al. [6], 80 patients)

the current study, a general preference for the inframammary incision site has been reported; however, the frequency of submuscular implantation is often higher. It is important to note that these studies differ in their design and methods used for data analysis and, therefore, the data cannot be directly compared.

In addition, experience with today's thicker, more cohesive silicone gel implants demonstrates a low complication rate and high level of patient acceptance [6, 9]. The PERTHESE implants have a unique microtextured envelope that may contribute to the surgeon's favorable experience in this study and to the low level of complications experienced. It is also possible that these implants are less likely to rupture or result in gel bleed; however, studies over a longer period are necessary to address these questions.
Acknowledgments The authors thank Emily Garcia, Ph.D., for editorial assistance.

Open Access This article is distributed under the terms of the Creative Commons Attribution Noncommercial License which permits any noncommercial use, distribution, and reproduction in any medium, provided the original author(s) and source are credited.

\section{References}

1. PERTHESE [package insert]. Bornel, France: Groupe PEROUSE PLASTIE, 1999

2. Auclair E, Staub S (2005) Round and anatomical mammary implants. Respective advantages and disadvantages. Ann Chir Plast Esthet 50:505-516 
3. Brown MH, Shenker R, Silver SA (2005) Cohesive silicone gel breast implants in aesthetic and reconstructive breast surgery. Plast Reconstr Surg 116(3):768-779

4. Hedén P, Boné B, Murphy DK, Slicton A, Walker PS (2006) Style 410 cohesive silicone breast implants: safety and effectiveness at 5 to 9 years after implantation. Plast Reconstr Surg 118(6):12811287

5. Bengtson BP, Van Natta BW, Murphy DK, Slicton A, Maxwell GP (2007) Style 410 highly cohesive silicone breast implant core study results at 3 years. Plast Reconstr Surg 120(7 Suppl 1):40S-48S

6. Niechajev I, Jurell G, Lohjelm L (2007) Prospective study comparing two brands of cohesive gel breast implants with anatomic shape: 5-year follow-up evaluation. Aesthetic Plast Surg 31:697-710

7. Cunningham B, McCue J (2009) Safety and effectiveness of Mentor's MemoryGel implants at 6 years. Aesthetic Plast Surg 33:440-444

8. Spear SL, Murphy DK, Slicton A, Walker PS (2007) Inamed silicone breast implant core study results at 6 years. Plast Reconstr Surg 120(7 Suppl 1):8S-16S

9. Fruhstorfer BH, Hodgson ELB, Malata CM (2004) Early experience with an anatomical soft cohesive silicone gel prosthesis in cosmetic and reconstructive breast implant surgery. Ann Plast Surg 53:536-542 